\title{
Photochemical Ring-Opening Reaction in 2(1H)-Pyrimidinones: A Matrix Isolation Study
}

\author{
Leszek Lapinski, ${ }^{\dagger,}{ }^{\dagger}$ Hanna Rostkowska, ${ }^{\dagger}$ Artem Khvorostov ${ }^{\dagger}{ }^{\dagger}$ Rui Fausto,${ }^{\ddagger}$ and \\ Maciej J. Nowak*, \\ Institute of Physics, Polish Academy of Sciences, Al. Lotnikow 32/46, 02-668 Warsaw, Poland, \\ and Department of Chemistry, University of Coimbra, P-3004-535 Coimbra, Portugal
}

Received: April 29, 2003; In Final Form: June 20, 2003

\begin{abstract}
Photoreactions induced by UV-B $(290-320 \mathrm{~nm})$ irradiation were studied for 1-methyl-2(1H)-pyrimidinone and 1-methylcytosine monomers isolated in low-temperature inert gas matrixes. A Norrish type I $\alpha$-cleavage reaction leading to open-ring conjugated isocyanate was observed for 1-methyl-2(1H)-pyrimidinone. The structure of the photoproduct was identified by comparison of its experimental IR spectrum with the spectrum theoretically calculated at the DFT(B3LYP)/6-31++G(d,p) level. The main indication of isocyanate as a photoproduced species was the appearance in the infrared spectrum recorded after UV irradiation of a very strong band at a characteristic frequency of $2263 \mathrm{~cm}^{-1}$. Observation of a new band at nearly the same frequency in the spectrum of UV-irradiated monomeric 1-methylcytosine may suggest that also in the case of this compound a conjugated isocyanate is photoproduced.
\end{abstract}

\section{Introduction}

Ultraviolet light induces photoreactions in chromatin of living cells. As a result of these photoreactions, lesions occur in the genetic material that can be carcinogenic or lethal to irradiated cells. The known photoreactions of nucleic acid bases yield photoproducts such as cytosine photohydrates, pyrimidine cyclobutane dimers, pyrimidine (6-4) pyrimidone adducts, and their Dewar valence isomers. ${ }^{1-3} \mathrm{An}$ important class of changes in irradiated chromatine is UV-induced DNA-protein crosslinking. ${ }^{4}$ Shetlar and co-workers ${ }^{5-7}$ proposed that one of the mechanisms of radiation-induced cross-linking can be a photoreaction of cytosine with amino groups of histone amino acids, for example, lysine. In a series of investigations, these authors demonstrated that UV irradiation of cytosine dissolved in aqueous solutions in the presence of amines or alcohols leads to open-ring photoproducts in which the cytosine and amine (or alcohol) moieties are covalently bound. The mechanism of these photoreactions was not elucidated. Nishio and coworkers $^{8-11}$ studied photoreactions of 1-aryl-2(1H)-pyrimidinones dissolved in benzene solutions containing amines or alcohols. Open-ring photoproducts analogous to those obtained from cytosine were isolated from the UV-irradiated solutions. Conjugated isocyanate, generated in a Norrish type I $\alpha$-cleavage process, was proposed to be a primary product of the photoreaction, although no direct proof of transient isocyanate was provided.

Norrish type I $\alpha$-cleavage reactions are among the classic reactions of organic photochemistry. In a series of recent papers, Diau et al. ${ }^{12-15}$ presented a contemporary insight into the fundaments of the mechanism of this class of photoreactions.

For cyclic carbonyl compounds, in which the carbonyl group is attached directly to a six-membered ring and linearly conjugated with two $\mathrm{C}=\mathrm{C}$ double bonds, Norrish type I reactions

\footnotetext{
* To whom correspondence should be addressed. E-mail: mjnow@ ifpan.edu.pl.

Polish Academy of Sciences.

$\doteqdot$ University of Coimbra.
}

were observed as early as $1968 .{ }^{16}$ The classic examples of such a reaction leading to conjugated ketenes as primary photoproducts are those observed for 2,4-cyclohexadienone ${ }^{17-20}$ and $\alpha$-pyrone. ${ }^{21-23}$ For these compounds, the single bond $(\mathrm{C}-\mathrm{C}$ or $\mathrm{C}-\mathrm{O})$ is cleaved upon UV excitation. The production of conjugated ketenes as direct photoproducts was proven by observation of characteristic, very intense bands at ca. 2140 $\mathrm{cm}^{-1}$ in the IR spectra of UV-irradiated monomeric compounds trapped in low-temperature matrixes. Conjugated ketenes were also identified as primary photoproducts through the appearance of IR bands in the 2139-2131 $\mathrm{cm}^{-1}$ spectral region in experiments in which matrix-isolated nitrogen heterocyclic compounds such as $2(1 H)$-pyridinone, ${ }^{24} 4(3 H)$-pyrimidinone ${ }^{25,26}$ or $3(2 H)$-pyridazinone ${ }^{27}$ were irradiated with UV light. For these compounds, the ring-opening photoreaction went through the splitting of the alpha $\mathrm{C}-\mathrm{N}$ single bond.

In principle, generation of conjugated isocyanates in analogous photoprocesses could be expected. Furthermore, detection of photoproduced species with isocyanate groups should be easy in a matrix isolation experiment combined with FTIR spectroscopy: the isocyanate moiety should manifest itself by a very intense infrared absorption band appearing within the characteristic frequency range $2280-2260 \mathrm{~cm}^{-1}$. Intense bands lying within this frequency range were observed in the infrared spectra of simple, stable isocyanates: methylisocyanate ${ }^{28}$ and ethylisocyanate. ${ }^{29}$ However, to the best of our knowledge, conjugated isocyanates produced in an $\alpha$-cleavage photoreaction have never been directly observed so far.

In the present work, we used matrix isolation technique combined with FTIR detection to directly observe primary products of the photoreactions occurring upon UV-B irradiation of 1-methyl-2(1H)-pyrimidinone and 1-methylcytosine.

\section{Experimental Section}

1-Methylcytosine (98\%) was obtained from Aldrich and was used without further purification. 1-Methyl-2(1H)-pyrimidinone was prepared by methylation of the parent $2(1 H)$-pyrimidinone, using the method described by Curd and Richardson. ${ }^{30}$ Prior to 


\section{CHART 1: 1-Methyl-2(1H)-pyrimidinone}

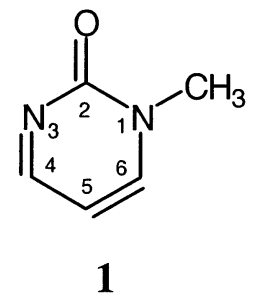

the matrix isolation experiments, the compound was purified by recrystallization from ethanol and by vacuum sublimation. To prepare the matrixes, the compounds were sublimated from a miniature glass oven placed in the vacuum chamber of a continuous flow helium cryostat using electrical heating. The vapors of the compound were frozen together with a large excess of the inert gas (argon or nitrogen) on a CsI window cooled to $10 \mathrm{~K}$. The argon and nitrogen matrix gases were of spectral purity, as supplied by Linde AG and Technische Gase, Leipzig.

The infrared spectra were recorded with $0.5 \mathrm{~cm}^{-1}$ resolution in the range $4000-400 \mathrm{~cm}^{-1}$, using a Thermo Nicolet Nexus FTIR spectrometer equipped with a $\mathrm{KBr}$ beam splitter and a DTGS detector. Integral intensities of the IR absorption bands were measured by numerical integration.

Matrixes were irradiated with light from the HBO200 highpressure mercury lamp, fitted with a water filter and a cutoff filter transmitting light with $\lambda>320 \mathrm{~nm}, \lambda>295 \mathrm{~nm}$, or $\lambda>$ $270 \mathrm{~nm}$. Typical irradiation time was $1 \mathrm{~h}$.

\section{Computational Section}

Molecular geometries were optimized using the density functional theory with the Becke's three-parameter exchange functional and gradient-corrected functional of Lee, Yang, and Parr (DFT(B3LYP)). ${ }^{31}$ All calculations were performed using the Gaussian 98 program. ${ }^{32}$ The standard 6-31++G(d,p) basis set was used in all cases. At optimized geometries, the DFT(B3LYP) harmonic vibrational frequencies and IR intensities were calculated. To correct for systematic shortcomings of the applied methodology (mainly for anharmonicity), the predicted vibrational wavenumbers were scaled down with a single factor equal to 0.98 .

The barriers for transition from one structure to the other were calculated at the MP2/6-31++G(d,p) level, ${ }^{33}$ using the coordinatedriven minimum energy path method. For a series of fixed values of the driving coordinate, all other parameters defining molecular geometry were optimized using the popt $=$ tight option of the Gaussian program. Energy was calculated for each of the optimized geometries.

\section{Results and Discussion}

Photoreaction of 1-Methyl-2(1H)-pyrimidinone. The infrared spectrum of 1-methyl-2(1H)-pyrimidinone monomers (Chart 1) isolated in Ar matrix is presented in Figure 1A. This spectrum is essentially the same as that previously reported by Smets et al. ${ }^{34}$ Upon UV $(\lambda>320 \mathrm{~nm})$ irradiation, the initial spectrum of 1-methyl-2(1H)-pyrimidinone disappeared almost completely. A new spectrum with a dominating extremely strong, comparatively broad, and structured band at $2263 \mathrm{~cm}^{-1}$ emerged (Figure 1B). The frequency, complex pattern with many maxima, and very high intensity are characteristic of a band due to the "antisymmetric" stretching vibration of the isocyanate $(-\mathrm{N}=\mathrm{C}=\mathrm{O})$ group. ${ }^{28,29}$ The integral intensity of this new band was more than twice that of the band corresponding to the $\mathrm{C}=\mathrm{O}$ stretching vibration in the initial closed-ring form.

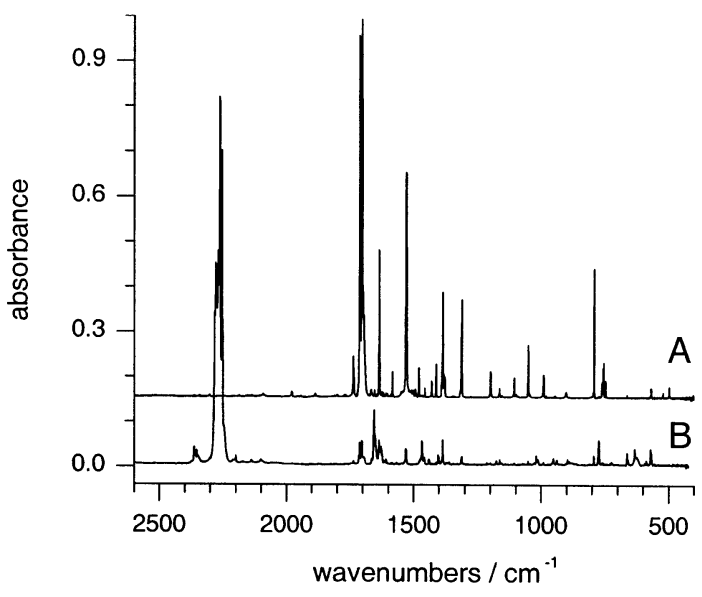

Figure 1. Infrared spectrum of 1-methyl-2(1H)-pyrimidinone isolated in an Ar matrix: (A) after deposition of the matrix; (B) after $1 \mathrm{~h}$ of $\mathrm{UV}(\lambda>320 \mathrm{~nm})$ irradiation.

In agreement with the experimental observations, DFT calculations predict an extremely high intensity for the "antisymmetric" $-\mathrm{N}=\mathrm{C}=\mathrm{O}$ stretching band $\left(1772 \mathrm{~km} \mathrm{~mol}^{-1}\right)$ of the open-ring, conjugated isocyanate and a considerably lower intensity (526 $\mathrm{km} \mathrm{mol}^{-1}$ ) for the carbonyl stretching band of the closed-ring species.

Upon subsequent UV $(\lambda>270 \mathrm{~nm})$ irradiation, a reverse photoreaction leading to a partial (ca. 25\%) recovery of the initial closed-ring form was observed. This experimental result (presented in Figure 2) clearly indicates that the studied photoreaction is a photoisomerization and not a photodecomposition process. Not equal decline of the components of the complex absorption at $2263 \mathrm{~cm}^{-1}$ upon the $\mathrm{UV}(\lambda>270 \mathrm{~nm})$ irradiation suggests that more than one conjugated isocyanate isomer was photoproduced. The phototransformations of 1-methyl$2(1 H)$-pyrimidinone monomers isolated in a nitrogen matrix were analogous to those observed for the compound isolated in solid argon (see Figure S1, Supporting Information).

Conjugated ketenes ${ }^{17-21,23}$ resulting from the photochemical ring opening of compounds such as $\alpha$-pyrone or 2,4-cyclohexadienone are often schematically presented as structure 2 (Chart 2). However, it seems improbable that this conformation really corresponds to the species frozen in low-temperature matrixes. The barrier between such a structure and the deep minimum of the closed-ring molecule $\mathbf{1}$ is very low. In the case of 1-methyl2(1H)-pyrimidinone, theoretical calculations predict for the open-ring structure 2 an energy barrier for ring closure as low as $2.1 \mathrm{~kJ} \mathrm{~mol}^{-1}$ (MP2), see Figure 3. With such a low-energy barrier, the open-ring molecule, which still possesses excess energy after excitation, can easily revert to the much more energetically stable closed-ring structure. Structure $\mathbf{3}$ also does not seem to correspond to one of the observed isomers of the photoproduct. The barrier for the flip of the isocyanate group leading from structure $\mathbf{3}$ to structure $\mathbf{2}$ is also very low $(1.7 \mathrm{~kJ}$ $\mathrm{mol}^{-1}, \mathrm{MP} 2$ ), and the energy of structure $\mathbf{3}$ is higher than that of structure $\mathbf{2}$. Therefore, structure $\mathbf{3}$ can easily convert to $\mathbf{2}$ and, subsequently, to the stable closed-ring form. Structures $\mathbf{2 a}$ and $\mathbf{3 a}$ are overcrowded and were not predicted by the theoretical calculations to correspond to energy minima. The four structures mentioned above have a cis orientation at the $\mathrm{C} 4=\mathrm{C} 5$ olefinic bond. The stabilization of these four forms in UV-irradiated matrixes seems improbable. However, there is experimental evidence of the presence in UV-irradiated matrixes of other cis structures. The clearly seen feature in the experimental spectrum of the photoproduct is the (relatively strong) 

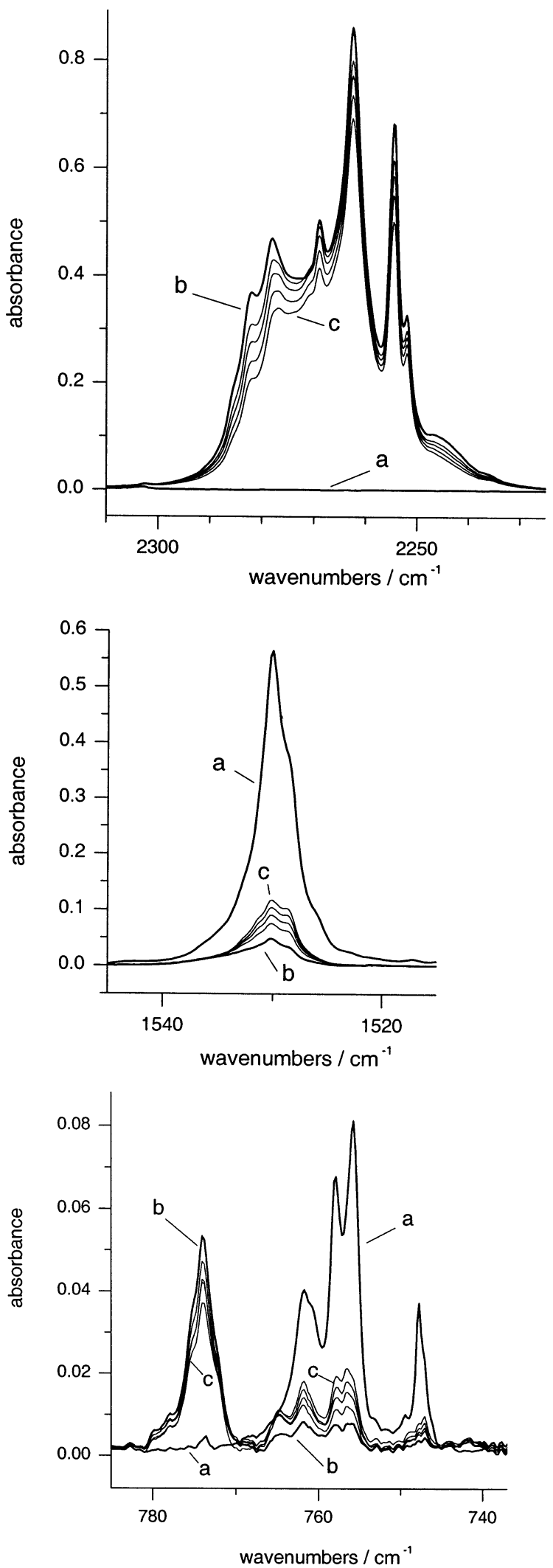

Figure 2. Portions of the infrared spectrum of 1-methyl-2(1H)pyrimidinone isolated in an Ar matrix: (a) after deposition of the matrix; (b) after $1 \mathrm{~h}$ of UV $(\lambda>320 \mathrm{~nm})$ irradiation; (c) after subsequent 16 min of UV $(\lambda>270 \mathrm{~nm})$ irradiation. Traces between traces $b$ and $c$ present the progress of the UV $(\lambda>270 \mathrm{~nm})$-induced photoreaction and correspond to irradiation times of 2,4 , and $8 \mathrm{~min}$.

band at $774 \mathrm{~cm}^{-1}$ (Figure 4A). Analogous absorption was observed at $779 \mathrm{~cm}^{-1}$ in the spectrum recorded after UV irradiation of 1-methyl-2(1H)-pyrimidinone isolated in the $\mathrm{N}_{2}$

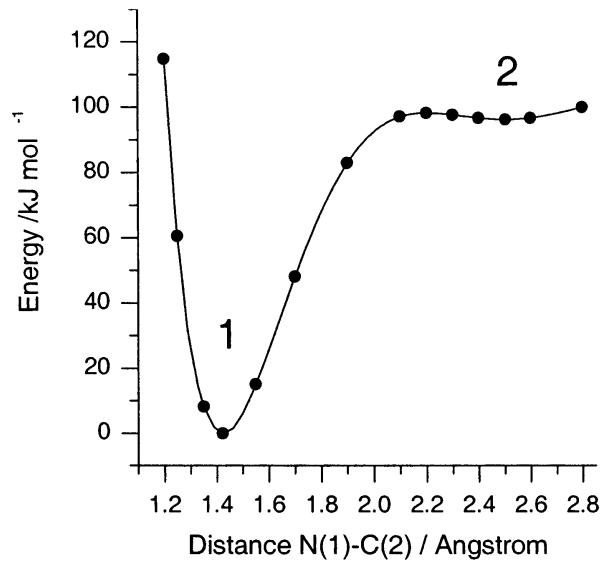

Figure 3. $M P 2 / 6-31++G(d, p)$ calculated potential energy curve for conversion from the open-ring form 2 to the closed-ring structure of 1-methyl-2(1H)-pyrimidinone (deep minimum at $1.42 \AA$ ). Each point was calculated by fixing the value of the distance between atoms N1 and $\mathrm{C} 2$ and optimizing all other parameters defining the geometry of the system. The calculated energy at the closed-ring minimum was -377.7907536 hartree.

\section{CHART 2: Structures of the Conjugated Isocyanate Photochemically Generated from 1-Methyl-2(1H)-pyrimidinone}<smiles>CN=CC=CN=C=O</smiles>

2<smiles>C/N=C/C=C\N=C=O</smiles>

3<smiles>C/N=C/C=C\N=C=O</smiles>

4
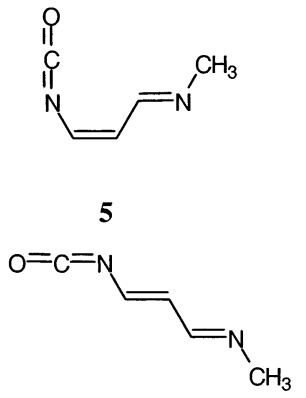

6

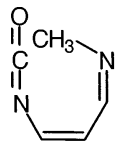

$\mathbf{2 a}$<smiles>C/N=C\C=C/N=C=O</smiles>

3a<smiles>CN=C/C=C\N=C=O</smiles>

$4 \mathbf{a}$

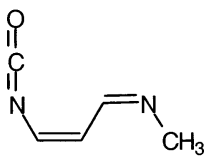

$5 \mathbf{a}$ matrix. According to the theoretical calculations, this band should correspond to the concerted out of plane (wagging) inphase vibration of the two cis hydrogen atoms at the $\mathrm{C} 4=\mathrm{C} 5$ double bond. The DFT(B3LYP)/6-31++G(d,p) calculations predict a medium-intensity band in this frequency range only for the cis isomers of the conjugated isocyanate molecule (Figure $4 \mathrm{C})$. In the predicted spectra of all trans isomers, the whole $900-650 \mathrm{~cm}^{-1}$ region is free from bands of significant intensity. On the basis of the comparison between the experimental observation and the spectra theoretically predicted for all 

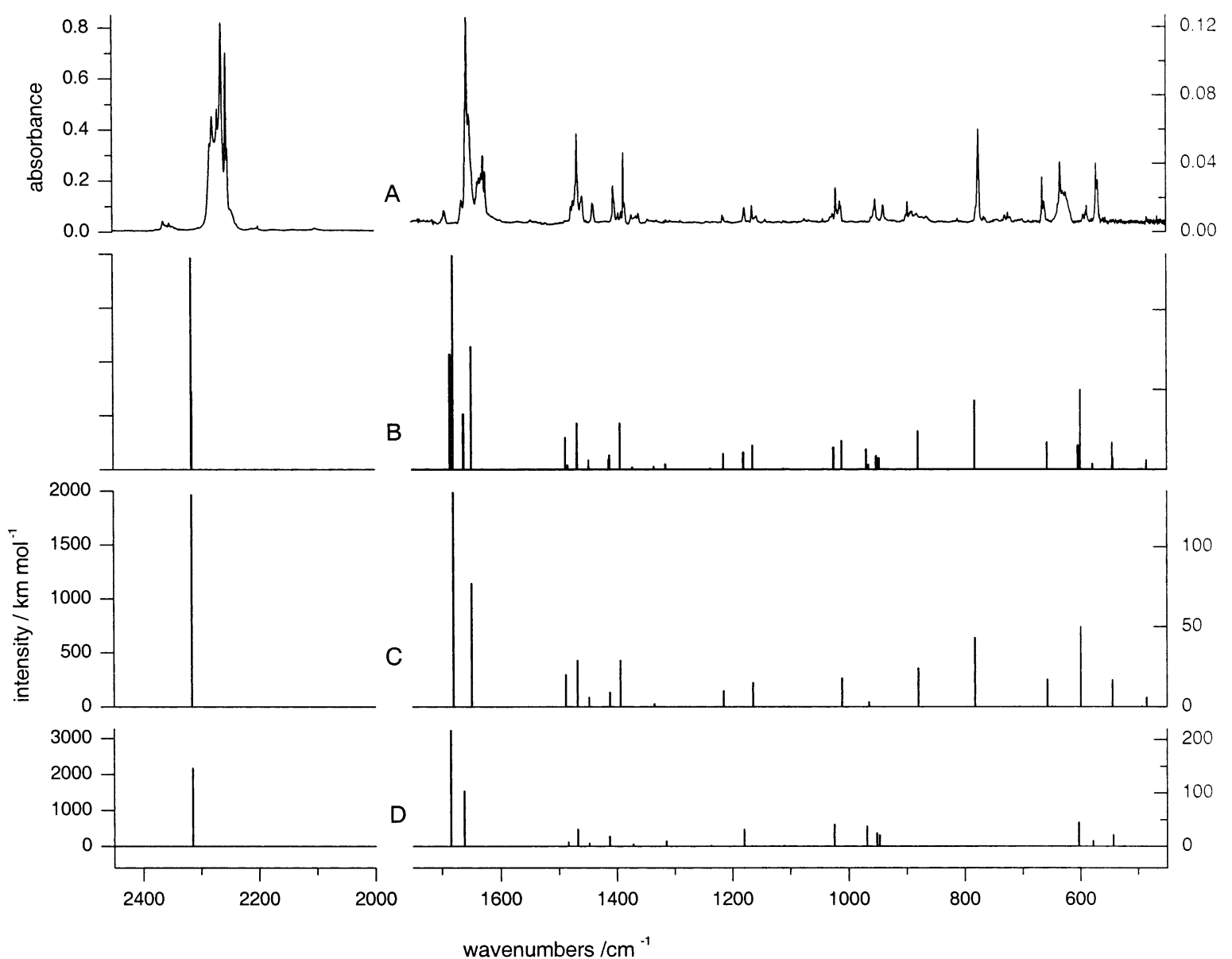

Figure 4. Infrared spectrum of (A) the photoproduct obtained by UV $(\lambda>320 \mathrm{~nm})$ irradiation of 1-methyl-2(1H)-pyrimidinone isolated in an Ar matrix (bands due to the remains of nonreacted 1-methyl-2(1H)-pyrimidinone were removed by subtraction of the initial spectrum, multiplied by a scale factor, from the spectrum recorded after irradiation), (C) the form $\mathbf{4}$ of the conjugated isocyanate calculated at the DFT(B3LYP)/6-31++G(d,p) level, (D) the form 6 of the conjugated isocyanate calculated at the DFT(B3LYP)/6-31++G(d,p) level, and (B) the superposition of traces C and D.

possible structures of the conjugated isocyanate (see Chart S1 in the Supporting Information), we may then postulate that isomers of the photoproduct with the cis orientation at the $\mathrm{C} 4=$ C5 double bond are observed. This, of course, does not exclude the possible simultaneous presence of some trans forms in the UV-irradiated matrix. As mentioned above, among the eight possible cis structures, forms $\mathbf{2}, \mathbf{2 a}, \mathbf{3}$, and $\mathbf{3 a}$ do not seem to be good candidates for species stabilized after the photoreaction. Hence, the discussion can be simplified to consideration of only the four remaining cis forms, which can be divided into two groups: one consisting of structures $\mathbf{4}$ and $\mathbf{5}$ and the other of $\mathbf{4 a}$ and 5a. Forms 5 and $\mathbf{5 a}$ are higher in energy than forms 4 and $\mathbf{4 a}$, respectively. The barrier separating $\mathbf{4}$ and $\mathbf{5}$ (or $\mathbf{4 a}$ and 5a) is the barrier for the torsion of the isocyanate group. The results of the theoretical calculation of this barrier are presented in Figure 5. The low predicted barrier of $3.1 \mathrm{~kJ} \mathrm{~mol}^{-1}$ suggests that the shallow minima corresponding to forms $\mathbf{5}$ and $\mathbf{5 a}$ should be depopulated when the open-ring system still possesses excess energy after the photoreaction. Therefore, only two structures ( 4 and $4 \mathbf{a}$ ) with cis orientation of the groups attached to the $\mathrm{C} 4=\mathrm{C} 5$ bond can be expected to be experimentally observed. Among the predicted infrared spectra for all possible structures of the conjugated isocyanate, those calculated for isomers $\mathbf{4}$ and 4a best reproduce the experimentally observed pattern (the calculated spectra of isomers $\mathbf{4}$ and $\mathbf{4 a}$ are very similar). Comparison of the experimental spectrum of the photoproduct with the calculated spectrum of form $\mathbf{4}$ is presented in Figure 4.

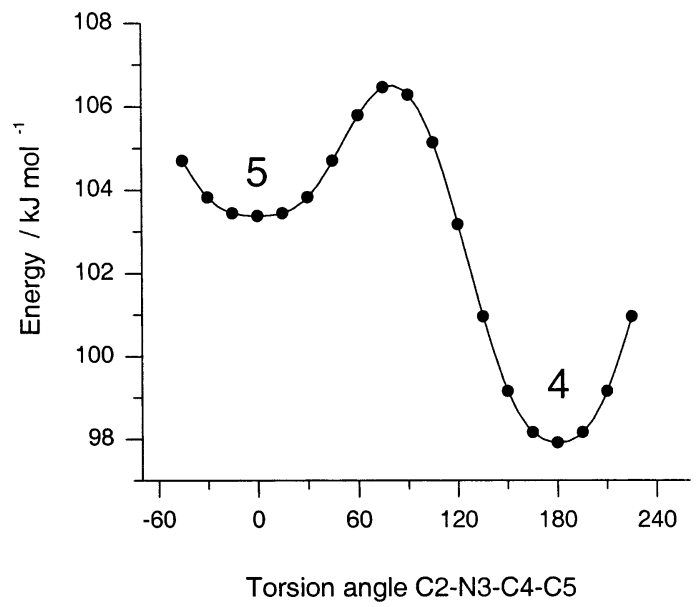

Figure 5. MP2/6-31++G(d,p) calculated potential energy curve for interconversion between forms $\mathbf{4}$ and $\mathbf{5}$ of the open-ring conjugated isocyanate. Each point was calculated by fixing the value of the torsional angle $\mathrm{C} 2-\mathrm{N} 3-\mathrm{C} 4-\mathrm{C} 5$ and optimizing all other parameters defining the geometry of the system. Energy of the closed-ring form was chosen as the reference (zero relative energy) level.

In the trans isocyanate isomers, the concerted out of plane vibration of the three hydrogen atoms attached to the carbon atoms in the open-ring chain gives rise to IR band(s) predicted in the region around $950 \mathrm{~cm}^{-1}$. No bands of significant intensity were predicted at these frequencies for the cis isomers. Two bands are clearly observed (in Ar matrix at 952 and $938 \mathrm{~cm}^{-1}$; 


\section{SCHEME 1: UV-Induced Ring-Opening Reaction in 1-Methyl-2(1H)-pyrimidinone}<smiles></smiles>

1

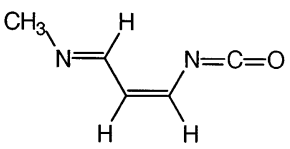

4

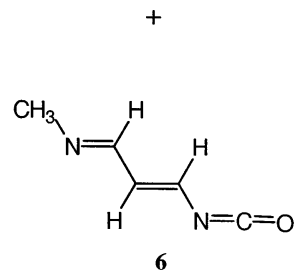

in $\mathrm{N}_{2}$ matrix at 956 and $940 \mathrm{~cm}^{-1}$ ) in this region of the experimental spectrum, and this fact suggests that trans isomers of the open-ring isocyanate were also produced in the studied photoreaction. On the basis of considerations similar to those described above for the cis isomers, structure $\mathbf{6}$ could be selected as the most probable trans form stabilized in the matrix. A graphical comparison of the superposition of the theoretical spectra of the forms $\mathbf{4}$ and $\mathbf{6}$ with the experimental spectrum of the photoproduct generated upon UV irradiation of 1-methyl$2(1 H)$-pyrimidinone is presented in Figure 4. Good agreement between the experimental spectrum and the results of the theoretical simulations strongly supports (i) the assignment of the conjugated isocyanate as the photoproduct and (ii) the conclusion that the most stable cis and trans forms of the isocyanate (both with a stretched molecular backbone) are stabilized in the matrixes (Scheme 1).

Photoreactions of 1-Methylcytosine. The infrared spectrum of 1-methylcytosine monomers isolated in Ar matrix (Figure $6 \mathrm{~A}$ ) is the same as those reported previously. ${ }^{35-37}$ About $6-8 \%$ of the matrix-isolated 1-methylcytosine ${ }^{36}$ adopts the imino-oxo tautomeric form (Chart 3), which coexists in the matrix with the dominating amino-oxo tautomer. Szczesniak et al. ${ }^{36}$ reported that the syn and anti isomers of the imino-oxo form interconvert between each other upon UV irradiation of the matrix. In the experiments on 1-methylcytosine carried out within the present work, the syn and anti isomerization of the imino-oxo tautomer upon UV $(\lambda>320 \mathrm{~nm})$ irradiation was also observed. When the matrix-isolated 1-methylcytosine was irradiated with the UV $(\lambda>295 \mathrm{~nm})$ light, a decrease of the IR bands of the dominating amino-oxo tautomer occurred, along with the anti $\rightarrow$ syn photoreaction of the minor imino-oxo form. This was accompanied by the appearance of a new, comparatively broad, and structured band with peak intensity at $2261 \mathrm{~cm}^{-1}$ (Figure $6 \mathrm{~B})$. Although the spectral position of this new band nearly coincides with that of the band at $2263 \mathrm{~cm}^{-1}$ observed in the case of irradiated 1-methyl-2(1H)-pyrimidinone, the analogy between the photoreactions of the two compounds is not completely straightforward. First, the intensity of the new band at $2261 \mathrm{~cm}^{-1}$, corresponding to consumption of $82 \%$ of the initial form of 1-methylcytosine, is several times lower than that of the band at $2263 \mathrm{~cm}^{-1}$ observed in the case of 1-methyl$2(1 H)$-pyrimidinone. Second, the bands of the syn imino-oxo photoproduct dominate the spectrum recorded after UV irradiation. These bands complicate, or make practically impossible, a detailed analysis of the IR spectrum of other photoproducts in the IR region below $1800 \mathrm{~cm}^{-1}$.

An almost exact coincidence of the frequencies of the bands at 2263 and $2261 \mathrm{~cm}^{-1}$, appearing in the spectra of matrix-

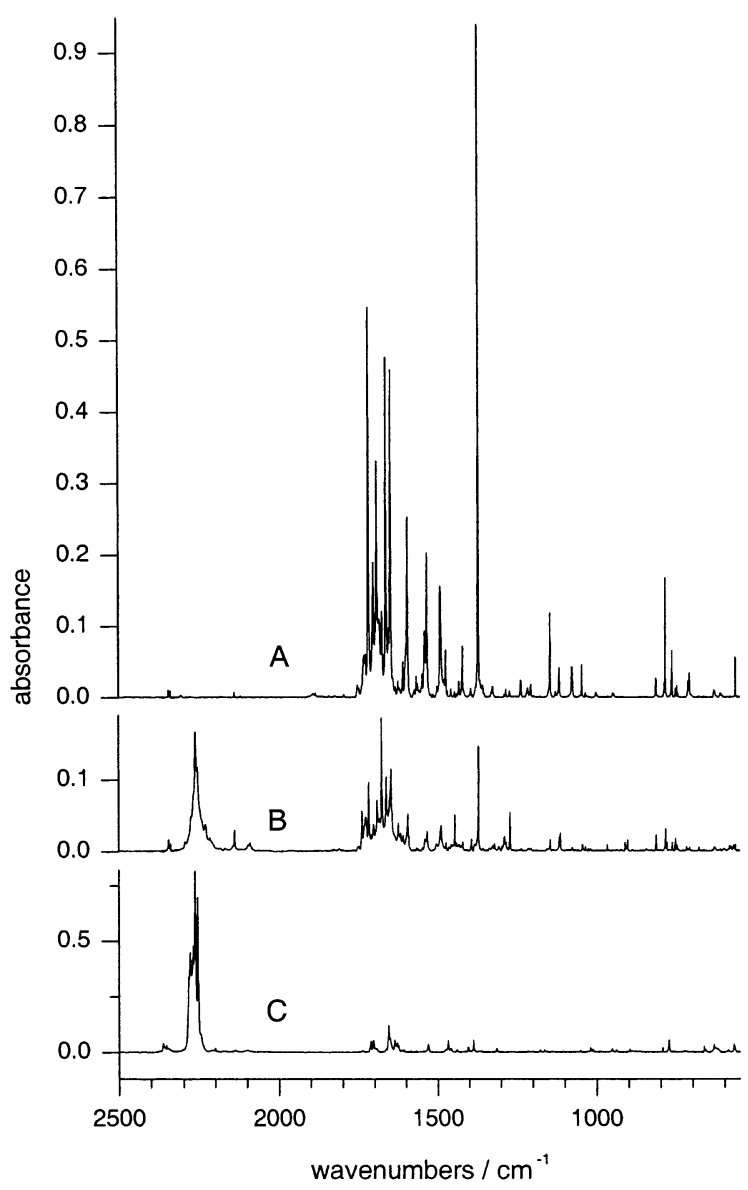

Figure 6. Infrared spectrum of (A) 1-methylcytosine isolated in an Ar matrix recorded immediately after deposition, (B) 1-methylcytosine isolated in an Ar matrix after $2 \mathrm{~h}$ of $\mathrm{UV}(\lambda>295 \mathrm{~nm})$ irradiation, and (C) UV-irradiated (1 h, $\lambda>320 \mathrm{~nm}$ ) 1-methyl-2(1H)-pyrimidinone.

CHART 3: Amino-oxo and Imino-oxo Forms of 1-Methylcytosine<smiles>Cn1ccc(N)nc1=O</smiles><smiles>Cn1ccc(=N)[nH]c1=O</smiles><smiles></smiles>

anti

isolated 1-methyl-2(1H)-pyrimidinone and 1-methylcytosine upon near UV irradiation (Figure 6, traces B and C), as well as the structural similarity of both compounds, could suggest that ring opening to conjugated isocyanate occurs also for 1-methylcytosine. However, we want to stress that in the case of 1-methylcytosine the observations made within the present work should be treated only as an indication of the possibility of conjugated isocyanate photoproduction and not as a basis for positive identification of the photoproduct structure.

Discussion. Interpretation of the observed effects of UV irradiation of both matrix-isolated pyrimidinones in terms of ring-opening Norrish type I reactions with conjugated isocyanates as primary photoproducts would lead to a simple interpretation of the experiments previously carried out for 1-aryl-2(1H)-pyrimidinones ${ }^{8,9}$ and cytosines ${ }^{5-7}$ dissolved in solutions containing alcohols or amines. Reactions of isocyanates with alcohols or amines are well-known and widely used in the polymer industry. The carbon atom in the $-\mathrm{N}=\mathrm{C}=\mathrm{O}$ moiety is electrophilic and susceptible to the attack of nuceophilic 
SCHEME 2: Reactions of Isocyanates with Alcohols and Amines

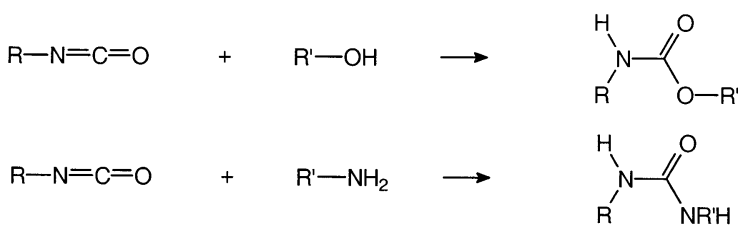

SCHEME 3: The Reaction between a Conjugated Isocyanate and an Alcohol ${ }^{a}$

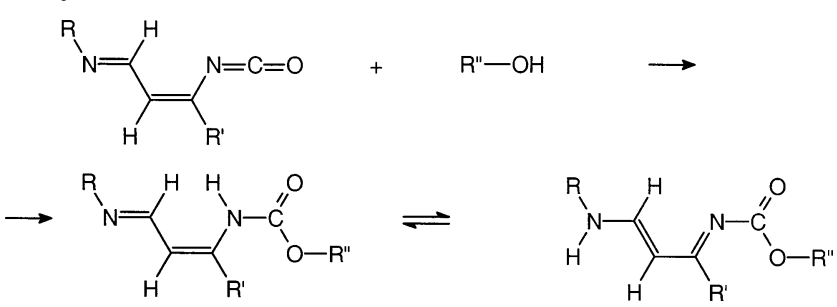

${ }^{a} \mathrm{R}=\mathrm{CH}_{3}$ (this work), $\mathrm{H}$ (ref 6), aryl (refs 9 and 11); $\mathrm{R}^{\prime}=\mathrm{H}$ (for $2(1 H)$-pyrimidinone), $\mathrm{NH}_{2}$ (for cytosine); $\mathrm{R}^{\prime \prime}=$ aliphatic.

\section{SCHEME 4: The Reaction between a Conjugated Isocyanate and an Amine ${ }^{a}$}

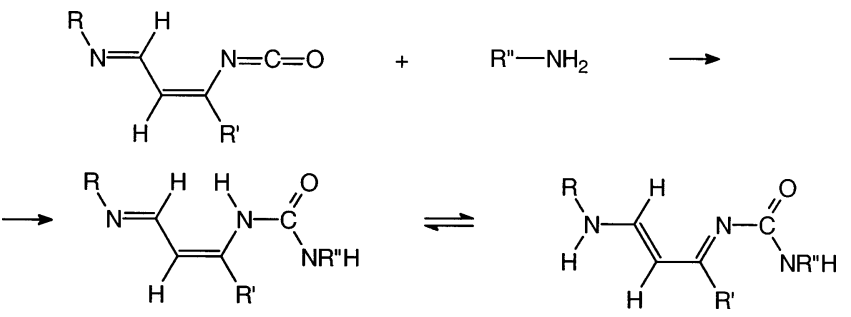

${ }^{a} \mathrm{R}=\mathrm{CH}_{3}$ (this work), $\mathrm{H}$ (ref 6), aryl (refs 9 and 11); $\mathrm{R}^{\prime}=\mathrm{H}$ (for $2(1 H)$-pyrimidinone), $\mathrm{NH}_{2}$ (for cytosine); $\mathrm{R}^{\prime \prime}=$ aliphatic.

reagents. The classic schemes of the reactions of isocyanates with alcohols or amines ${ }^{38-40}$ are shown in Scheme 2. Direct application of these patterns to the reaction of the postulated open-chain isocyanate transient leads to final products presented in Schemes 3 and 4. Such structures of final photoproducts were experimentally identified by Nishio et al., ${ }^{8,9}$ and the structures of the photoproducts obtained by Shetlar et al. ${ }^{5-7}$ from UVirradiated cytosines differ from those presented in Schemes 3 and 4 only by a tautomerization of a proton (labile in protic solution conditions). Hence, interpretation of the results of the present matrix isolation study, together with the results of investigations of photoreactions of the studied compounds in solutions, in terms of Norrish type I reaction leading to conjugated isocyanates as primary product would give a consistent picture of ring-opening reactions in 2(1H)-pyrimidinones.

If a highly reactive conjugated isocyanate transient could be photoproduced from cytosine molecules in DNA of the living cell, then it would be easily trapped by, for example, an amino group of histone lysine, giving rise to a covalent DNA-histone cross-linking. A scheme based on ring opening of pyrimidine nucleic acid bases and covalent bonding with amino acids was considered by Shetlar et al. ${ }^{4,7}$ as one of the possible mechanisms of photoinduced DNA-protein cross-linking.

\section{Conclusion}

The results of the present matrix isolation study show that upon near UV irradiation 1-methyl-2(1H)-pyrimidinone opens its ring in the Norrish type I $\alpha$-cleavage process. The extremely strong band appearing at the characteristic frequency of 2263 $\mathrm{cm}^{-1}$ in the IR spectra recorded after UV irradiation, as well as the general agreement over the whole mid-IR range between the spectrum of the photoproduct and the spectrum theoretically predicted for the open-ring structure, proves that the conjugated isocyanate is the primary product of the photoreaction. The presence of the band at $2261 \mathrm{~cm}^{-1}$ in the IR spectra of UVirradiated 1-methylcytosine suggests that a conjugated isocyanate could be a photoproduct (or one of the photoproducts) also in the case of this compound. Interpretation of the observed photoreactions in terms of Norrish type I ring-opening processes allows a simple explanation of photochemical experiments carried out previously for 2(1H)-pyrimidinone compounds dissolved in benzene or aqueous solutions and opens an interesting possibility to explain one of the mechanisms of photoinduced DNA-protein cross linking.

Acknowledgment. R.F. acknowledges the financial support provided by the Portuguese Science Foundation, FCT (POCTI/ 43366/QUI/2001 research program).

Supporting Information Available: Figure S1 providing the infrared spectrum of 1-methyl-2(1H)-pyrimidinone isolated in a $\mathrm{N}_{2}$ matrix before and after $\mathrm{UV}(\lambda>320 \mathrm{~nm})$ irradiation and Chart S1 showing all possible structures of the conjugated isocyanate photochemically generated from 1-methyl-2(1H)pyrimidinone. This material is available free of charge via the Internet at http://pubs.acs.org.

\section{References and Notes}

(1) Cadet, J.; Berger, M.; Douki, T.; Morin, B.; Raoul, S.; Ravanat, J.-L.; Spinelli, S. Biol. Chem. 1997, 378, 1275.

(2) Cadet, J.; Vigny, P. In Bioorganic Photochemistry; Morrison, H., Ed.; Wiley: New York, 1990; Vol. 1, pp 1-272.

(3) Cadet, J.; Anselmino, C.; Douki, T.; Voituriez, L. J. Photochem. Photobiol. B 1992, 15, 277.

(4) Meisenheimer, K. M.; Koch, T. H. Crit. Rev. Biochem. Mol. Biol. 1997, 32, 101

(5) Shetlar, M. D.; Hom, K.; Distefano, S.; Ekpenyong, K.; Yang, J. Photochem. Photobiol. 1988, 47, 779.

(6) Shaw, A. A.; Shetlar, M. D. Photochem. Photobiol. 1989, 49, 267.

(7) Hom, K.; Strahan, G.; Shetlar, M. D. Photochem. Photobiol. 2000, $71,243$.

(8) Nishio, T.; Omote, Y. J. Chem. Soc., Perkin Trans. 1 1984, 239.

(9) Nishio, T.; Katahira, K.; Omote, Y. J. Chem. Soc., Perkin Trans. 1 1981, 943.

(10) Nishio, T.; Kashima, C. Rev. Heteroatom. Chem. 1995, 13, 149.

(11) Nishio, T. Liebigs Ann. Chem. 1992, 71.

(12) Diau, E. W.-G.; Kotting, C.; Zewail, A. H. ChemPhysChem 2001 $2,273$.

(13) Diau, E. W.-G.; Kotting, C.; Zewail, A. H. ChemPhysChem 2001, 2, 294.

(14) Diau, E. W.-G.; Kotting, C.; Solling, T. I.; Zewail, A. H. ChemPhysChem 2002, 3, 57.

(15) Solling, T. I.; Diau, E. W.-G.; Kotting, C.; DeFeyter, S.; Zewail, A. H. ChemPhysChem 2002, 3, 79.

(16) Hobson, J. D.; Al Holly, M. M.; Malpass, J. R. J. Chem. Soc., Chem. Сотmun 1968, 764.

(17) Quinkert, G. Pure Appl. Chem. 1973, 33, 285.

(18) Griffiths, J.; Hart, H. J. Am. Chem. Soc. 1968, 90, 3297.

(19) Griffiths, J.; Hart, H. J. Am. Chem. Soc. 1968, 90, 5296.

(20) Chapman, O. L.; Lassila, J. D. J. Am. Chem. Soc. 1968, 90, 2449

(21) Chapman, O. L.; McIntosh, C. L.; Pacansky, J. J. Am. Chem. Soc 1973, 95, 244.

(22) Pong, R. G. S.; Shirk, J. S. J. Am. Chem. Soc. 1973, 95, 248.

(23) Kranz, A. J. Am. Chem. Soc. 1974, 96, 4992.

(24) Nowak, M. J.; Lapinski, L.; Fulara, J.; Les, A.; Adamowicz, L. J. Phys. Chem. 1992, 96, 1562.

(25) Lapinski, L.; Fulara, J.; Nowak, M. J. Spectrochim. Acta 1990, 46A, 61.

(26) Lapinski, L.; Nowak, M. J.; Les, A.; Adamowicz, L. J. Am. Chem. Soc. 1994, 116, 1461

(27) Lapinski, L.; Fulara, J.; Czerminski, R.; Nowak, M. J. Spectrochim. Acta 1990, 46A, 1087. 
(28) Sullivan, J. F.; Heusel, H. L.; Zunic, W. M.; Durig, J. R. Spectrochim. Acta 1994, 50A, 435.

(29) Sullivan, J. F.; Durig, D. T.; Durig, J. R.; Cradock, S. J. Phys. Chem. 1987, 91, 1770.

(30) Curd, F. H.; Richardson, D. N. J. Chem. Soc. 1955, 1853.

(31) Lee, C.; Yang, W.; Parr, R. G. Phys. Rev. 1988, 37, 785.

(32) Frisch, M. J.; Trucks, G. W.; Schlegel, H. B.; Scuseria, G. E.; Robb,

M. A.; Cheeseman, J. R.; Zakrzewski, V. G.; Montgomery, J. A., Jr.; Stratmann, R. E.; Burant, J. C.; Dapprich, S.; Millam, J. M.; Daniels, A. D.; Kudin, K. N.; Strain, M. C.; Farkas, O.; Tomasi, J.; Barone, V.; Cossi, M.; Cammi, R.; Mennucci, B.; Pomelli, C.; Adamo, C.; Clifford, S.; Ochterski, J.; Petersson, G. A.; Ayala, P. Y.; Cui, Q.; Morokuma, K.; Malick, D. K.; Rabuck, A. D.; Raghavachari, K.; Foresman, J. B.; Cioslowski, J.; Ortiz, J. V.; Stefanov, B. B.; Liu, G.; Liashenko, A.; Piskorz, P.; Komaromi, I.; Gomperts, R.; Martin, R. L.; Fox, D. J.; Keith, T.; Al-Laham, M. A.; Peng, C. Y.; Nanayakkara, A.; Gonzalez, C.; Challacombe, M.; Gill, P. M W.; Johnson, B. G.; Chen, W.; Wong, M. W.; Andres, J. L.; Head-Gordon,
M.; Replogle, E. S.; Pople, J. A. Gaussian 98, revision A.7; Gaussian, Inc.: Pittsburgh, PA, 1998.

(33) Møller, M.; Plesset, M. S. Phys. Rev. 1934, 46, 618.

(34) Smets, J.; Destexhe, A.; Adamowicz, L.; Maes, G. J. Phys. Chem. $B$ 1997, 101, 6583 .

(35) Kuczera, K.; Szczesniak, M.; Szczepaniak, K. J. Mol. Struct. 1988, $172,73$.

(36) Szczesniak, M.; Leszczynski, J.; Person W. B. J. Am. Chem. Soc. 1992, 114, 2731.

(37) Smets, J.; Adamowicz, L.; Maes, G. J. Phys. Chem. 1996, 100, 6434.

(38) Raspoet, G.; Nguen, M. T.; McGarraghy, M.; Hegarty, A. F. J. Org. Chem. 1998, 63, 6878.

(39) Ulrich, H. Chemistry and Technology of Isocyanates; John Wiley \& Sons: New York, 1996; Chapter 1.2.

(40) Morrison, R. T.; Boyd, R. N. Organic Chemistry, 6th ed.; Benjamin Cummings: San Francisco, CA, 1992; Chapter 31.8. 